\title{
The Study of Stream Litter Accumulation as a Model for Cross- Disciplinary, Transformative, Affordable, and Scalable Undergraduate Research Experiences in STEM
}

\author{
Matthew B. Parks ${ }^{1 *}$, Emily P. Hendryx ${ }^{2}$, Andrew T. Taylor ${ }^{1}$
}

1 Department of Biology, University of Central Oklahoma, UNITED STATES

2 Department of Mathematics and Statistics, University of Central Oklahoma, UNITED STATES

*Corresponding Author: mparks10@uco.edu

Citation: Parks, M. B., Hendryx, E. P., \& Taylor, A. T. (2021). The study of stream litter accumulation as a model for cross-disciplinary, transformative, affordable, and scalable undergraduate research experiences in stem. Interdisciplinary Journal of Environmental and Science Education, 17(3), e2245. https://doi.org/10.21601/ijese/10935

ARTICLE INFO ABSTRACT

Received: $\quad$ Undergraduate learning in STEM is enhanced by participation in tractable and relevant research 16 September 2020 projects. Simultaneously, it is challenging to design meaningful research opportunities that remain affordable, engage students in most aspects of the scientific process, and offer opportunities for

Accepted: transformative learning experiences. We designed a collaborative 12 -week undergraduate research

4 February 2021 project based on the quantification of litter along two urban streams in the Oklahoma City (United States) metropolitan area, addressing a regional issue with global implications. This study engaged six undergraduate students at a low cost with commonly available equipment. Three faculty involved brought expertise in physical stream characterization, ecology, statistics, and mathematical modeling, allowing students to approach data analysis from multidisciplinary and collaborative perspectives. Students participated in nearly all stages of scientific research, including a brief literature survey, data collection and analysis toward addressing research questions, interpretation of results, and presentation at a scientific meeting. Post-project surveys revealed that students held highly favorable perceptions in relation to overarching project goals, including improvements in data management and quantitative analysis, in comprehension of scientific abstracts, in grasping the scientific process, and in skill development toward future career goals. Student perceptions regarding the importance of participation in generating data, interest in future data analysis, and the importance of receiving financial compensation for participation were less favorable and varied. Despite increased interest in conducting future field work, interest in pursuing a career in research was slightly diminished after participation in the project. Evidence of transformative learning existed in the targeted areas of scholarly activity and health and wellness. We discuss the benefits of our study design, including suggestions for improvement and the adaptability of this study for other educational contexts.

Keywords: undergraduate research, STEM, multidisciplinary, affordable, transformative learning, litter

\section{INTRODUCTION and BACKGROUND}

Undergraduate research experiences (UREs) are known to facilitate STEM learning for undergraduate students, including historically under-represented groups (e.g. National Academy of Sciences, 2017; Russell, Hancock, \& McCullough, 2007). Direct student participation in STEM problem-solving also results in statistically significant increases in student performance and decreases in failure rates (Freeman et al., 2014). In addition, interdisciplinary and collaborative research experiences in STEM have

Copyright (C) 2021 by Author/s and Licensed by Veritas Publications Ltd., UK. This is an open access article distributed under the Creative Commons Attribution License which permits unrestricted use, distribution, and reproduction in any medium, provided the original work is properly cited. 
been recommended for improved training and success in the workforce (Jang, 2016). Implementation of UREs is often challenging due to financial constraints, institutional inertia, and other hurdles (Bradforth et al., 2015; Shadle, Marker, \& Earl, 2017; Zydney, Bennett, Abdus, \& Bauer, 2002), with the result that undergraduate STEM learning, particularly in the classroom, is still overwhelmingly dominated by traditional lecture-style instruction (Stains et al., 2018). Maximizing effectiveness in STEM learning strategies is thus an ongoing challenge, but one that is most effectively approached with creative strategies adapted to available faculty-, departmental-, and college-specific resources (Henderson, Beach, \& Finkelstein, 2011).

The Journal of Transformative Learning (https://jotl.uco.edu/index.php/jotl/index)

describes transformative learning as the "active process of learning that encourages seeing new things, seeing old things differently, and reconceptualizing mindsets," and transformative learning is accepted as an impactful component of effective STEM education (Montgomery \& Fernandez-Cardenas, 2018). Exposure to largely unaddressed or unrecognized problems in a local community creates an opportunity for transformative learning beyond scientific research, including areas such as civic and cultural awareness, and health and environmental outcomes. The study of litter accumulation in local streams presents an affordable means to create a transformative STEM URE with clear connections to a global problem. The accumulation of manufactured, solid wastes in freshwater and marine environments has led to pervasive habitat degradation, threats to human health, and loss of biodiversity (Lasut et al., 2018; Rochman et al., 2013). Plastics and other consumptive goods accumulate in freshwater stream channels and their floodplains, eventually moving downstream and contributing up to approximately 2.41 million metric tons of plastic marine debris annually (Derraik, 2002; Lebreton et al., 2017). As few urban or rural communities are immune to litter accumulation issues, the study of litter is relevant to students across the globe and can serve as an opportunity for students to actively engage in research questions surrounding issues facing their local communities and the global community at large.

To leverage the benefits of UREs in the context of a relevant yet resource-limited research project, we designed and implemented an undergraduate research experience focused on litter accumulation in urban streams. Our project relied on primarily lowcost equipment, aimed to facilitate transformative learning experiences as framed by the Student Transformative Learning Record (STLR) initiative at the University of Central Oklahoma (UCO) (https://www.uco.edu/academic-affairs/stlr/), and is adaptable to a variety of educational settings. The objectives of the current report are to (1) describe our project in its initial implementation, (2) provide evidence supporting transformative learning through reflections from participating students, (3) provide data regarding student perception of project impact on research and professional skills, and (4) offer suggestions for improving upon and adapting this project for future use.

\section{METHODS}

\section{Project Design and Student Recruitment}

Project planning among the three PIs began in early Fall 2019, including developing a tractable timeline for the project (Table 1). The project timeline was structured based on anticipated student skillsets, project funding, and expected student participation in a state-wide undergraduate research symposium. During project development, the PIs submitted a proposal to UCO'S STLR program and were awarded funds to provide limited hourly pay to undergraduates involved in this study. Initially inspired by observations of local litter accumulation by one of the PIs, and the global significance of litter waste, the project idea evolved over several weeks through faculty conversations and a shared interest in interdisciplinary undergraduate research opportunities. The approved proposal to UCO STLR focused both on scientific merit and educational opportunities for participating students. The project's science aims were to improve understanding of litter accumulation in local metropolitan waterways. The project's educational goals were to provide to students a multidisciplinary, hands-on experience in fieldwork and sampling techniques, management/analysis/modeling involving real data collected by the students, and presenting research at an academic meeting. These primary project goals served as the foundation for assignment of specific analysis questions in Week 4 (Table 1). These questions were largely formulated by project PIs based on student backgrounds and the quality of the data collected in Weeks 1-3, but also included a working dialogue with participating students during data collection stages.

A total of six undergraduates (two per PI, class level freshman to senior) were recruited from UCO courses taught by the three PIs based on overlap between individual interests of the students and PIs. For students applying statistical and modeling techniques, previous basic coursework in these areas was required. Students pursuing mathematical modeling were recruited specifically based on prior course experience with the corresponding faculty 
Table 1. Weekly timeline and activities for 12-week stream litter accumulation undergraduate research project. Weeks 1-3 were completed in the field; Weeks 4-12 were completed on campus, with part of Week 11 completed at Oklahoma Research Day hosted by Southwestern Oklahoma State University in Weatherford, Oklahoma

\begin{tabular}{|c|c|}
\hline Week(s) & Activities and assignments \\
\hline $1-3$ & - $\quad$ Collecting field data \\
\hline 4 & $\begin{array}{l}\text { - Formulating specific research questions (predominantly PI-led) } \\
\text { - } \quad \text { Assigning data curation duties } \\
\text { - Installing and introducing software }\end{array}$ \\
\hline 5 & $\begin{array}{ll} & \text { Writing draft abstracts } \\
\text { - } & \text { Structuring draft posters } \\
\text { - } & \text { Assessing data curation progress } \\
\text { - } & \text { Instructing students on specific software and analyses }\end{array}$ \\
\hline 6 & $\begin{array}{l}\text { - } \quad \text { Peer-reviewing draft abstracts } \\
\text { - } \quad \text { Completing poster titles and author lists } \\
\text { - } \quad \text { Completing data curation }\end{array}$ \\
\hline 7 & $\begin{array}{l}\text { - Beginning initial data analyses } \\
\text { - } \quad \text { Drafting bullet points for all poster sections }\end{array}$ \\
\hline 8 & $\begin{array}{ll} & \text { Revising poster bullet points } \\
\text { - } & \text { Designing preliminary poster tables and figures } \\
\text { - } & \text { Continuing data analyses }\end{array}$ \\
\hline $9-10$ & $\begin{array}{ll}\text { - } & \text { Continuing data analyses } \\
\text { - } & \text { Revising poster design and content }\end{array}$ \\
\hline 11 & $\begin{array}{l}\text { - } \quad \text { Practicing and peer-reviewing poster presentations } \\
\text { - Finalizing and printing posters } \\
\text { - Presenting posters at research conference }\end{array}$ \\
\hline 12 & $\begin{array}{l}\text { - Meeting for post-project wrap-up } \\
\text { - Assigning: } \\
\text { - Literature review } \\
\text { - Technical report with summary } \\
\text { - } \text { Pransformative experience reflections questionnaire } \\
\end{array}$ \\
\hline
\end{tabular}

member. Other students were recruited through inclass announcements or in response to a student's individual expression of research interests. Students were assigned to different aspects of the data analysis based upon their previous coursework and their research interests.

\section{Field Data Collection}

A total of four sampling sites, split among two watersheds in the Oklahoma City Metropolitan Area, were chosen by the PIs based on upstream and downstream juxtaposition to a presumed pointsource of litter and reasonable distance from the UCO campus $(<20 \mathrm{~km})$. Data collection was conducted over three weekends in November and early December 2019, with sampling at each site lasting approximately 3-5 hours. Prior to each sampling event, overall objectives, justification for sample site selection, individual duties, and safety concerns were discussed with students. Waterproof waders and boots were made available to a majority of the students conducting field work, but those without on a given data collection day remained on the bank to record data and assist in collecting floodplain data.

A field collection datasheet (Supplementary Data) was designed with student input. At each site, delineation of stream channel unit type (i.e., riffle, run, or pool) and delimitation of bank-full widths were completed via discussion among students and PIs. Across each stream channel unit type at a site, three transects were marked at $25 \%, 50 \%$, and $75 \%$ of the channel unit length and perpendicular to channel flow (Figure 1) using either demarcated poly-cord rope or a field measuring tape. At five proportionally spaced points along each transect, and at additional points extending $5 \mathrm{~m}$ past bank-full width into the floodplain, digital images for litter cover estimation were taken in standardized units (defined as the area within an $88 \mathrm{~cm}$ diameter hula hoop) using either digital or cell phone cameras. Students also completed three independent "rapid visual counts" of litter through timed walks along the first transect (i.e., 25\%, shown in Figure 1) for each stream channel unit at each site, as an alternative measure of litter abundance. Stream depth and water 


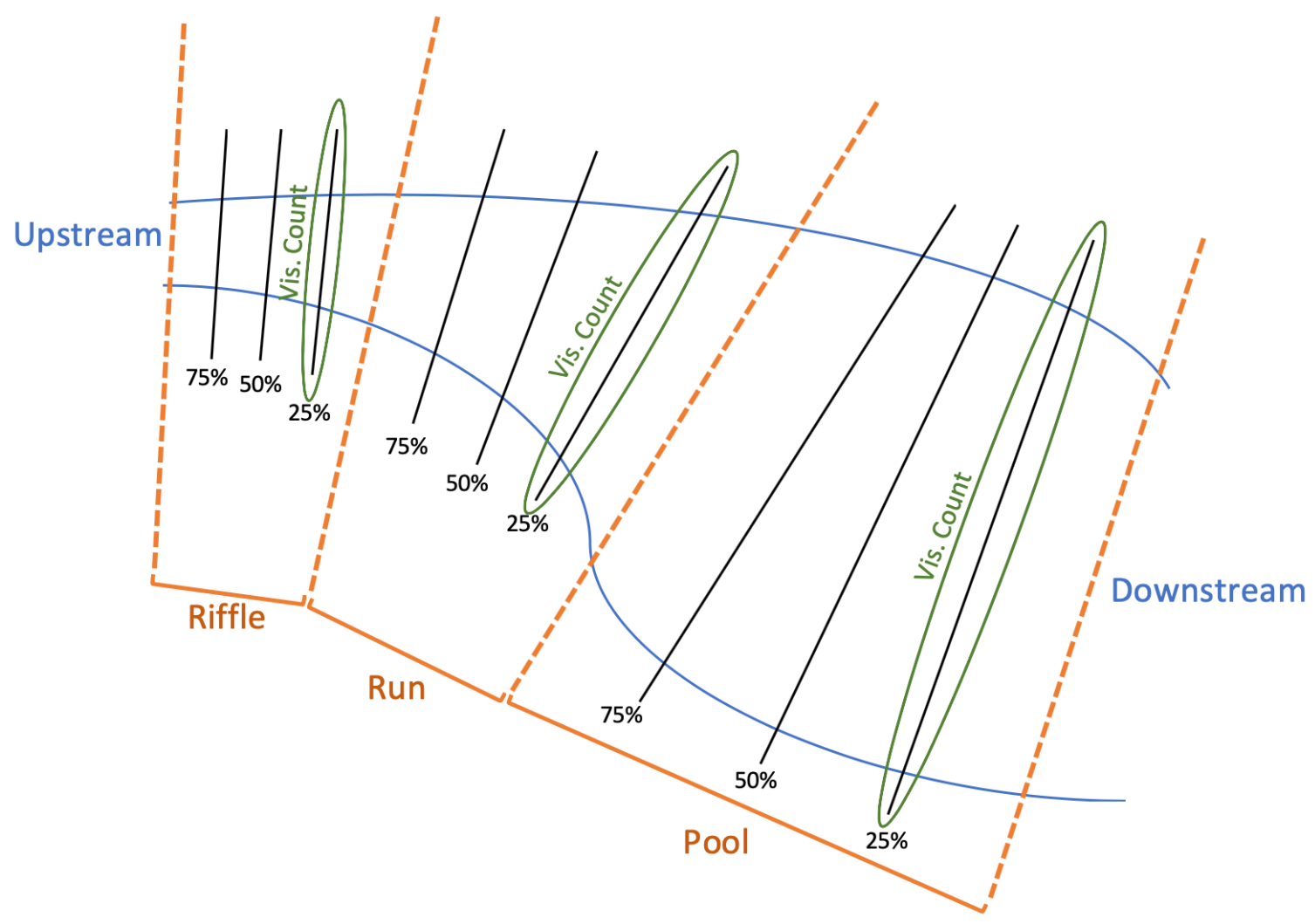

Figure 1. Diagram of transect sampling performed at an example site

clarity were estimated using a $2 \mathrm{~cm}$ diameter PVC tube demarcated at $10 \mathrm{~cm}$ intervals. A list of basic field gear with estimated costs in US Dollars is reported in Table 2. Pictures of example field sites, techniques and equipment, and the undergraduate field crew can be seen in Figure 2.

\section{Data Processing and Analyses}

Digital images were compiled and organized using a shared, designated Google Drive directory (https://www.google.com/drive/). Four students performed visual counts of litter pieces from digital images with each image analyzed by at least two students. The two remaining students were then assigned the task of final image processing, which involved both adjudicating inconsistent litter counts and estimating litter surface area in individual images using the free image-processing software ImageJ (https://imagej.nih.gov/ij/). As these students were new to using the software, the PIs provided a brief guide for selecting litter within an image and determining the resulting surface area in Image J.

Each student was responsible for independent data analysis in one of three focal areas using the corresponding analytical software and tools:

1) Geospatial trends in litter accumulation in relation to stream morphology: Microsoft Excel
Table 2. Estimated cost for the minimally required equipment

\begin{tabular}{lcc}
\hline \multicolumn{1}{c}{ Equipment Item } & $\begin{array}{c}\text { Approx. \# } \\
\text { Needed }\end{array}$ & $\begin{array}{c}\text { Total } \\
\text { Estimated } \\
\text { Cost } \\
\text { (USD) }\end{array}$ \\
\hline $\begin{array}{l}\text { Chest waders with } \\
\text { boots* }\end{array}$ & 3 & 270 \\
$\begin{array}{l}50-m \quad \text { open reel } \\
\text { measuring tape** }\end{array}$ & 1 & 25 \\
$\begin{array}{l}\text { Write-in-rain paper for } \\
\text { datasheets }\end{array}$ & ---- & 20 \\
$\begin{array}{l}\text { PVC depth stick } \\
\text { Hula-hoop }\end{array}$ & 2 & 4 \\
$\begin{array}{l}\text { Personal camera (e.g., } \\
\text { cell phone) }\end{array}$ & 2 & 3 \\
\end{tabular}

*Need for waders may depend on local environment and project design.

**A $50 \mathrm{~m}$ poly-cord rope with $0.5 \mathrm{~m}$ increments marked in colored tape was initially used but was more difficult to work with than a retractable reel tape.

was used for data manipulation and ESRI ArcMap for mapping. A license for ArcMap is maintained by UCO.

2) Statistical analyses of litter distribution: Statistical analyses were undertaken primarily using the software SPSS 

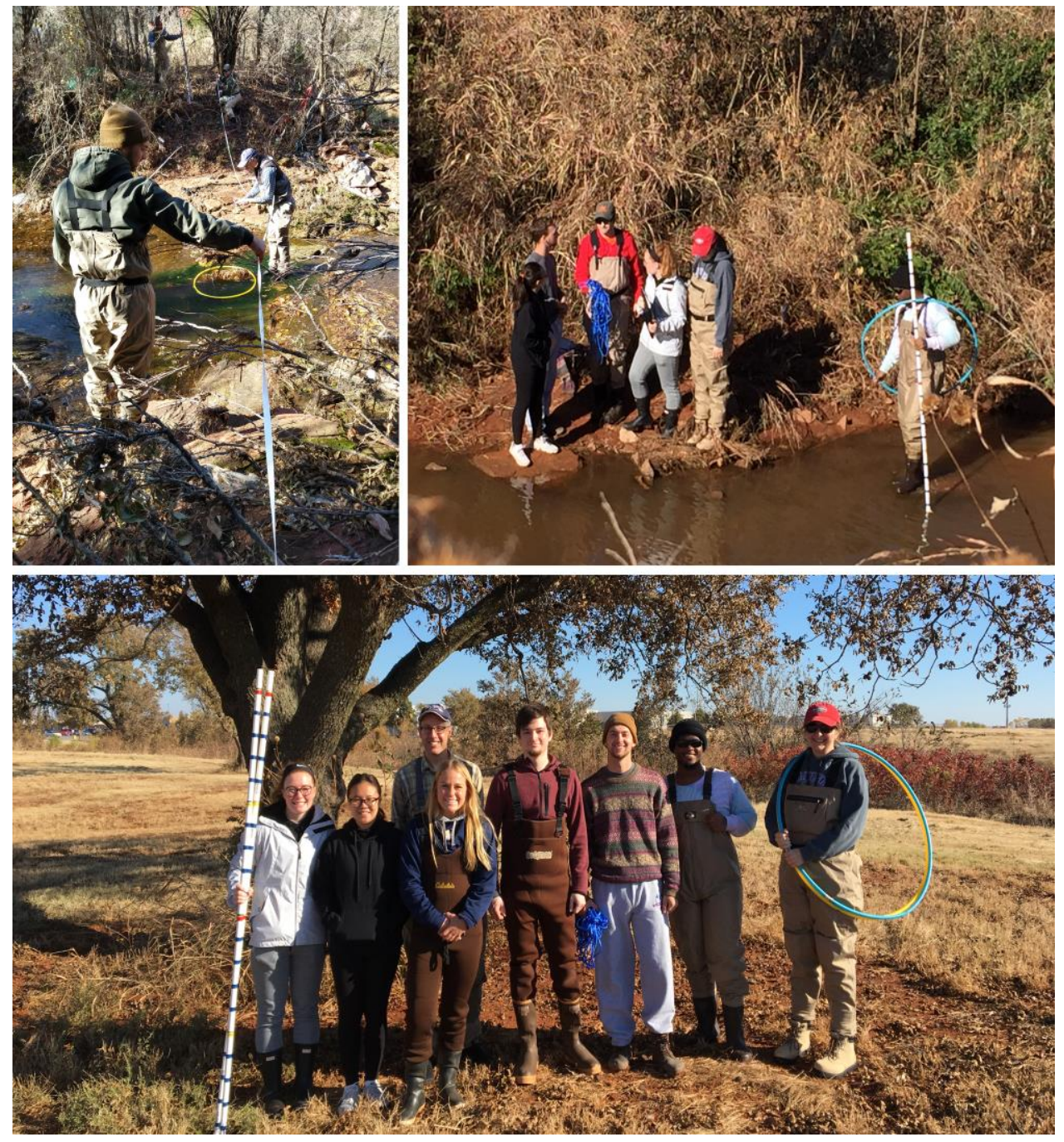

Figure 2. Students and faculty collecting litter accumulation data in the field

(https://www.ibm.com/products/spss-statistics) under a campus-wide usage license maintained by UCO.

3) Mathematical modeling of litter distribution using differential equations: Depending on the students' familiarity with different software, the solutions to the models were primarily derived using

MATLAB

(https://www.mathworks.com/products/matlab .html), freely available online calculators such as Symbolab (https://www.symbolab.com/) and WolfamAlpha

(https://www.wolframalpha.com/), Microsoft Excel.

\section{Poster Creation and Presentation}

Each student was responsible for the design and creation of their own research poster (using basic poster templates provided by the PIs) to describe their project and highlight their specific research questions, analyses, and results. Faculty and peer feedback was provided on poster design and content during weekly meetings in Weeks 5 through 11 of the project (Table 1). Students were also required to submit research abstracts and present their posters at an annual state-wide undergraduate research symposium (Oklahoma Research Day) during Week 11.

Technical Write-up and Literature Survey

Students were required to complete a brief (1-2 pages) final technical write-up summarizing their specific analyses on the research project. Additionally, each student was tasked with identifying three primary research articles focusing specifically on litter accumulation in freshwater urban environments outside of the United States. For each article, students identified the primary research question and conclusions, described the methods and results, and compared the findings to those of our project. While introducing students to the review process, this assignment was not intended to serve as a thorough literature review; the goal was to increase students' awareness of the global nature of litter 
accumulation, and the variability in scientific and cultural address specifically of urban and freshwater litter accumulation, within the time limitations of our project.

\section{Post-Project Reflections and Survey}

Project PIs designed two post-project artifacts probing student experiences (both provided as Supplementary Data). First, students were required to complete written responses to several reflective questions probing the level of their "transformative learning experience" in relation to four of UCO's "Central Six" transformative learning tenets (Global and Cultural Competencies; Health and Wellness; Research, Creative and Scholarly Activities; and Service Learning and Civic Engagement) (https://www.uco.edu/academicaffairs/transformative-learning/). In accordance with the STLR program at UCO, the level of each student's apparent transformation throughout the project for each tenet was evaluated by the PIs according to an established UCO STLR rubric (https://www.uco.edu/academic-

affairs/files/stlr/stlr-achievement-level-

descriptions.pdf). Second, students completed a short survey consisting of seven-point Likert-scale, relative ranking, and open-response questions to evaluate student perceptions of varied aspects of the project, including field data collections, data analysis, and poster presentation. The survey questions and design were approved by the UCO Institutional Review Board (IRB \#2020-044), and student participation was optional and anonymous. Likertscale responses were mathematically summarized by awarding the following point values for an answer: strongly disagree $=0$, disagree $=1$, somewhat disagree $=2$, neither agree nor disagree $=3$, somewhat agree $=4$, agree $=5$, strongly agree $=6$.

\section{RESULTS}

We highlight the results of our project in the following two areas: Student Research Outcomes and Overall Student Experiences. In Student Research Outcomes, we briefly summarize the questions our students investigated and the analytical approaches used. In Overall Student Experiences, we first broadly discuss students' research artifacts and responses to STLR reflection prompts regarding transformative learning experiences. We then provide more detailed results through responses to the post-project survey, highlighting potential strengths and weaknesses of the project based on student perceptions.

\section{Student Research Outcomes}

All six participating students addressed unique research questions and formulated and presented research posters at Oklahoma Research Day.

Geospatial trends in litter accumulation. One student focused on correlations between different measures of litter accumulation (i.e., point-counts, surface area estimates, or visual transects) at multiple spatial scales (i.e., transect, channel unit type, or entire sample site) using Excel to aggregate datasets and SPSS to conduct correlation analyses. Another student first plotted heatmaps of litter pointcounts over aerial images of each site. This student was also interested in how stream morphology affected litter accumulation across all sites, so the student compared average litter point-counts for inside bends (i.e., depositional areas) versus outside bends (i.e., erosional areas) and for floodplains versus in-channel point-counts.

Statistical analyses of litter distribution. Two students tested all three litter quantification measures (litter counts and surface area within hulahoop sampling units, and visual litter counts along $25 \%$ transects) to determine whether 1) stream channel unit type, 2) relative upstream/downstream location at a site, or 3) level of commercialization of the surrounding area, significantly impact litter distribution. Using both 1-way and 2-way ANOVA, students recovered channel unit type (riffles, pools) and level of commercialization as significant factors in litter distribution, but did not recover upstream vs. downstream locations within sites as significant factors. The two students involved in these efforts also discussed the implications of each of their findings toward the other's results.

Mathematical modeling using differential equations. Modeling efforts were completed by two students who had taken the junior-level Differential Equations course offered by the University. One student used a system of linear ordinary differential equations to model litter movement over time through different stream units. The other student approached the problem through a steady-state convection-diffusion model in an effort to model litter movement through space in each stream unit. Both students gained hands-on experience in deriving model parameters and initial/boundary conditions from real data; this was perhaps one of the most challenging pieces of model development, requiring the inclusion of additional generalizations/assumptions based on both the limited field data as well as hydrologic data available through the U.S. Geological Survey National Water Information

System (https://waterdata.usgs.gov/nwis/). With some parts of the model solutions derived by hand when 
feasible, students also generated model solutions using the computational tools mentioned in the previous section.

\section{Overall Student Experiences}

Artifacts and STLR reflections. Five of six students (referred to as Students "A" - "E" below) submitted responses to reflective writing prompts (prompts available in the Supplementary Data), and three students submitted literature review artifacts, providing opportunity for the PIs to gauge evidence of transformative learning experiences. Although likely influenced by our project design, the most meaningful experiences for our students fell within the two UCO STLR tenets of Research, Creative and Scholarly Activities (RCSA), and Health and Wellness (HW). There was also some evidence for development in our two other targeted tenets: Global and Cultural Competencies (GCC), and Service Learning and Civic Engagement (SLCE). Example student responses that highlight experiences related to each of these tenets are:

RCSA: "This project made me feel like a scientist and showed me so much about the research process.... I learned how to do field samples, data analysis, work, and communication with other scientists, how to present a poster, how to gather data, and so much more." - Student A

HW: “... after completing this project, I always bring my own reusable bags to Walmart and also persuade all my close friends to do that too." Student B

GCC: "I was able to see firsthand how our consumer culture does not put enough importance on mindfulness of our consumption, and that the careless consumption we participate in manifests in the local natural environments as the buildup of countless pieces of trash in all shapes and sizes. The experience has definitely reinforced my assumptions that our culture does not care enough about the environment that we live in." - Student C

SLCE: "One day I wish to present this issues [sic] to the higher authority to provide more funding for urban streams." - Student D

To gauge students' overall experiences, we asked them how they foresaw using what they had learned through this experience in the future. The response below emphasizes some of the overall experiences gained through participation in this particular study.
"With this experience, I have improved my public speaking.... I could see myself being involved in more research on the topic. Furthermore, I also loved getting to apply the differential equations outside the classroom. Getting to use data that I helped to collect was rewarding in itself, and it helped me to better understand how differential equations can be used to model real life scenarios. With this experience, I could foresee myself applying these same techniques in my career." Student E

Post-project survey. Four students completed the anonymous post-project survey with responses supporting an overall highly favorable and effective learning experience. None of these four students had participated in field research or presented a research poster prior to this project. Full survey questions and response summaries are available in the Supplementary Data, and response highlights are summarized below.

Students reported strongly improved understanding of challenges associated with field data collection over the course of the project (average response score \pm standard deviation $=5.75 \pm 0.5$ ) and that they would enjoy participating in field work in the future $(5.5 \pm 1.0)$. Students rated the value of participating in data collection favorably but slightly lower $(4.75 \pm 1.26)$. Three of four written responses to the query "How was field work useful?" made direct connections to students' aspirations beyond the University:

"It was useful in getting that on the job training that the normal classroom can't provide."

"It allowed me to ask complex questions about what I was trying to accomplish and how I might change my math to be more meaningful in the real world."

"The field work was valueable [sic] because it gave me expirence $[s i c]$ in research. This is useful to see if I thought I could make a career out of research."

Students reported that their quantitative analysis, data management, and computational skills improved $(5.25 \pm 0.96,5.25 \pm 0.5$, and $5.5 \pm 0.58$, respectively), but they were not as strongly inclined to enjoy future data analysis opportunities (4.5 \pm 1.29). Written responses to the query "How has your perception of data analysis changed?"focused largely on the challenges of accurately corralling a large dataset. For example:

"Data analysis is no joke." 

"Making these significant numbers digestible is
important..."

"I did not fully understand how data analysis happened in a project. I thought it would be as easy as a mathematical or statistcal [sic] word problem. However, there is much more than that on data analysis."

The experience of creating and presenting a research poster resulted in perceived improvements in presentation and abstract reading/writing skills (5.0 \pm 0.82 and $5.75 \pm 0.5$, respectively), and posters were viewed as valuable tools in improving understanding of field work and data analysis (5.5 \pm 0.58). Students also enjoyed interacting with visitors to their posters during Oklahoma Research Day (5.0 \pm 0.82; all students reported 6-10 visitors per poster), although preparation of posters during the week prior was considered stressful (5.25 \pm 0.96$)$. Written responses to the query "How was the poster presentation valuable?" emphasized the development of speaking skills and the importance of conveying scientific results. For example:

"The art of public speaking and the early exposure into prospective field."

\begin{abstract}
"Presenting is a valuable skill and it deepens the presenters [Sic] understanding of the information as well."

"The poster presentation was an incredibly valuable experience for me. It allowed me to convey the ideas that I had been working on in the months prior and taught me how to communicate those ideas effectively."
\end{abstract}

Overall, students considered the skills gained throughout the project as useful for future research $(5.75 \pm 0.5)$, career goals (5.5 \pm 0.58$)$, and understanding the scientific process $(5.5 \pm 0.58)$. Students reported increased appreciation for interdisciplinary research $(5.5 \pm 1.0)$ and rated the usefulness of interactions with both peers and faculty highly $(5.25 \pm 0.5$ and $5.75 \pm 0.75$, respectively) Despite positive responses regarding interest in future field work, students indicated their inclination toward a career in research was slightly higher before versus after the project, although this difference was not significant $(5.0 \pm 0.82$ and $4.5 \pm$ 1.0, respectively; $\mathrm{p}$-value for paired, two-tailed t-test $=0.495)$. The importance of financial compensation for participation was rated relatively low on average $(2.5 \pm 2.65)$; however, scores here ranged from zero (strongly disagree) to six (strongly agree).

\section{DISCUSSION}

With generally increased student experience in, and appreciation of, the research process, the undergraduate project implemented herein may be appealing to other educators at a variety of levels. In particular, this project is multidisciplinary, provides opportunity for transformative learning within the context of a relevant global issue, and could be adapted across different educational levels and geographical areas.

\section{Multidisciplinary Aspects}

Our case study focused on multidisciplinary research by coupling field work with geospatial, statistical, and mathematical modeling techniques for studying litter accumulation in local watersheds. As responses to the anonymous post-project survey suggest students appreciated the interdisciplinary nature of this specific project design, an additional benefit of our project is that many other STEM domains could be readily incorporated. For example, faculty with taxonomic expertise could guide students in plant, invertebrate, or fish surveys to test for correlations between biodiversity and litter or other anthropogenic impacts; faculty with engineering backgrounds might focus on hydrology or litter-concentrating features occurring in waterways; faculty with chemistry backgrounds might focus on water quality and the presence of chemical pollutants; etc. Importantly, the interaction of students and faculty working on the same system from different perspectives provides a valuable opportunity to expand students' creativity, make connections between their research inquiries and those of their peers, and increases their understanding of diverse STEM-based research strategies. Such research experiences may facilitate training of undergraduates that are more adept at tackling complex questions within interdisciplinary collaborations within their careers (Davis, Mahatmya, Garner, \& Jones, 2015).

\section{Transformative Aspects}

Although our study involved a small student sample size ( $\mathrm{n}=6$ students), we were still able to gain valuable feedback on transformative learning experiences through our applied UCO STLR reflections and post-project surveys. Students were involved in nearly all aspects of the project, offering input on stream unit selection, collecting data, analyzing data according to their study question(s), presenting their findings in an academic forum, and limited exploration of the scientific literature. Our project was eye-opening for our students who had otherwise not considered the ecological value of 
urban streams but were able to see first-hand the discord between natural ecosystem components (including wild animal tracks, clear water, fish, native flora, etc.) and litter (ranging from small bottlecaps to aluminum cans to tires, shopping carts, and bowling balls). In fields such as environmental education and environmental sustainability, educators use similarly immersive or discordant experiences in nature to facilitate transformative learning (lyer-Raniga \& Andamon, 2016; Singleton, 2015). Throughout the process of data collection and analysis, students also considered additional questions to pursue beyond this project. For instance, one student expressed interest in performing statistical analyses that would study litter accumulation in watersheds passing through neighborhoods with varying economic development. Students also had to address the question "What is litter?" both in the field and in the subsequent image review; this question prompted a group discussion highlighting the role of definitions and assumptions in framing specific scientific questions and revealed that additional studies would be necessary to account for broader/narrower definitions of litter. In addition, students recognized the possibility of including time-dependent terms/parameters in models to reflect seasonal environmental factors, a task that would require repeated field data collection at the selected sites.

As implemented, our project appeared to result in the greatest degree of transformation in the UCO STLR tenets of Research, Creative and Scholarly Activities, and Health and Wellness. However, focus could be shifted to more fully incorporate other transformative learning targets. Coupled with the notion of project adaptability, development of global and cultural awareness could be further enabled by applying a standardized sampling protocol (for example, Moore, Cover, \& A, 2007) combined with a citizen science-based data collection approach (Bonney et al., 2009; Dickinson, Zuckerberg, \& Bonter, 2010). This would allow for directly comparable data to be collected on a greatly expanded scale, including state-, country- or even world-wide. Direct engagement with local- and statelevel political and regulatory agencies and officials would also enhance civic engagement experiences (Green, 2012) and potentially improve student transformation through translation of scientific research into concrete civic outcomes (Thiry, Laursen, \& Hunter, 2011).

\section{Affordability Aspects}

Overall, the primary materials and data collection and analysis design of our study was affordable as implemented at a mid-sized regional university. We expect that many institutions or educational settings with limited financial and equipment resources would be able to utilize a version of our project. We used low-cost field equipment to collect our data, and we analyzed data with software packages that were of no direct cost. Although we used a mixture of free and proprietary software (under university-held license agreements), free and open-source software such as R, Python, QGIS, or GRASS GIS (to name a few) could have been used to complete our analyses or address additional research questions. The local nature of our field sites also helped reduce financial and time constraints. Waders were the most expensive piece of field equipment in our project, but they were primarily needed because of cold water temperatures. Future studies could be designed to preclude the need for waders; for example, if a study focused solely on litter observable from stream banks or present within floodplains. Similarly, if travel and sampling of similar stream sites would be costprohibitive, we suggest that our case study could be easily adapted to nearby, alternative environments such as roadways, fence lines, parking lots, marine beaches, or any other landscape feature that accumulates litter.

Our students were not awarded course credit for project participation but were compensated on a limited hourly basis through funding from the UCO STLR program. In our post-project survey, students rated the importance of financial compensation relatively low on average, although individual valuations of the statement "Getting paid to work on this project was an important factor in my decision to participate" were the most variable in our survey and ranged from "strongly disagree" to "strongly agree." This suggests that the successful implementation of UREs may be substantially impacted by individual students' financial constraints, a consideration of some successful comprehensive UREs and broader STEM educational approaches (Wilson, Iyengar, Pang, Warner, \& Luces, 2012). To ameliorate these impacts, we suggest compensation through course credit-hours where institutional financial resources are limiting or utilizing 'work-study' or alternative funding sources where possible or deemed critical for student support.

\section{Adaptability Aspects}

With six undergraduate students and three mentor faculty members, the post-project survey results support that students were satisfied with the amount of faculty oversight provided and enjoyed interacting with peers working on same- and acrossdiscipline research aims of a shared project. For faculty and students interested in receiving teaching and course credit, the 12 -week timeline we provide 
could be adjusted relatively easily to accommodate a longer semester or shorter quarter if presented as an independent research or research methods course opportunity. Repeating the study multiple semesters can allow for the inclusion of more students in the research process while potentially producing a richer, longitudinal data set, although our efforts are currently limited in this regard by the global COVID19 pandemic. The numbers of students participating could also likely be increased with limited increase in faculty effort or cost. For example, the number of sites sampled could be increased but fewer faculty might participate in data collection at a site, the numbers of questions/hypotheses addressed from a shared data set could be expanded, students could work in pairs, and expanded peer review strategies could be used during data analysis and poster assembly.

We targeted the level of our analyses to undergraduate STEM majors, although the general framework of our project should be adaptable to lower (K-12) educational levels by adjusting the data collection and analysis tools applied. In a similar study, Kiessling et al. (Kiessling et al., 2019) used transect-plots to characterize litter density and distribution along rivers in Germany. In comparison to our project, this "Plastikpiraten" study used citizen-science with targeted participation of students 10-16 years of age. Students collected litter density counts and identifications from fewer transects (up to 3) per river and only on bank areas adjacent to rivers. Higher level statistical analyses in this project were completed by participating faculty, while participating students were able to calculate simpler variables such as litter count density.

\section{Other Considerations}

While students were able to generate presentable research outcomes and their responses to this project were largely positive, there are a variety of aspects that deserve additional consideration and/or revision in future iterations. Some of these potential changes are mentioned above, including expanding the study to involve students and faculty from additional disciplines as well as further diversifying opportunities in transformative learning. Student completion of the literature search was likely impacted by changes in instructional formats due to the global COVID-19 pandemic, and future iterations of this project should likely incorporate the literature review through the duration of the project given its importance throughout the scientific process. We were also surprised that student interest in pursuing a career in research was slightly lower after than before the project, although this result was not statistically significant. We believe that the arduous nature of our field collection protocol, and the large amount of data that students had to manipulate and analyze while maintaining otherwise full course loads, were significant challenges for them, especially those that had fewer years as a STEM undergraduate prior to participating in our study. Because of this, the study, as implemented, may have the most benefit for junior- and senior-level students. Our project implementation also had a relatively rapid turnaround between data collection, analysis, and presentation, which was also challenging for students as supported by reported stress experienced by students in the week before presenting at Oklahoma Research Day. We suggest that future instructors carefully consider the corresponding course loads, educational levels, and research interests of participating students when designing an adaptation of this project to their own educational setting and, for example, expanding student participation in project design and question and hypothesis formulation.

Educators should also consider site-specific safety and ethical concerns in any future adaptations of this work (for example, stream flow levels, site topography, and site access permissions) and should always clearly communicate group safety protocols. In addition, although our sampling strategies were adequate for our research purposes-in fact, the comparison of field methods was a research question in our project design - a standardized protocol could be adopted globally for future works (for example, Gonzalez et al., 2016; Moore et al., 2007). Researchers have called for such standardization in order to improve models of how litter enters and travels through stream systems (Lebreton et al., 2017), which could ultimately better inform broad-scale remediation efforts and environmental policies.

\section{CONCLUSIONS}

The International Union for Conservation of Nature (IUCN) recognizes "garbage and solid waste" as a level 2 direct threat to be considered when assessing the conservation status of any taxon (https://www.iucnredlist.org/resources/classificati on-schemes), implying that such wastes could cause stress or proximate pressure that could contribute to imperilment (Fairweather, 2008). Developing future scientists and engaged citizens through relevant and tractable STEM research opportunities is an important strategy in addressing this and other issues of global concern. Through the support of the UCO STLR program, we were able to successfully complete a transformative, affordable, multidisciplinary research project wherein students engaged in the scientific research process outside of classroom settings while also providing an opportunity for students to engage in a global 
environmental issue at the local scale: litter accumulation in urban streams. We based the specific characteristics of our study design on the expertise of participating faculty, and we suggest that our project is highly amenable to adaptation based on student backgrounds as well as faculty and resources available at other institutions.

\section{ACKNOWLEDGEMENTS}

We acknowledge funding from the University of Central Oklahoma's Student Transformative Learning Record (STLR), a Department of Education Title III grant program. We thank Dr. Jenna Messick for her contributions in initial planning of this study and for loaning waders. We also thank Dr. James Bidlack, Dr. David Bass, and Dr. Jesse Byrne for letting us borrow field gear and waders.

\section{Statement of Consent}

Written consent was obtained from all participating students for publication of photographic images containing their likeness and anonymized written responses to STLR and postproject survey questions.

\section{REFERENCES}

Bonney, R., Cooper, C. B., Dickinson, J., Kelling, S., Phillips, T., Rosenberg, K. V., \& Shirk, J. (2009). Citizen science: A developing tool for expanding science knowledge and scientific literacy. Bioscience, 59(11), 977-984. https://doi.org/10.1525/bio.2009.59.11.9

Bradforth, S. E., Miller, E. R., Dichtel, W. R., Leibovich, A. K., Feig, A. L., Martin, J. D., ... Smith, T. L. (2015). University learning: Improve undergraduate science education. Nature, 523(7560), 282-284. https://doi.org/10.1038/523282a

Davis, S. N., Mahatmya, D., Garner, P. W., \& Jones, R. M. (2015). Mentoring undergraduate scholars: a pathway to interdisciplinary research? Mentoring \& Tutoring: Partnership in Learning, 23(5), 427-440. https://doi.org/10.1080/13611267.2015.1126166

Derraik, J. G. (2002). The pollution of the marine environment by plastic debris: a review. Mar Pollut Bull, 44(9), 842-852. https://doi.org/10.1016/s0025-326x(02)00220-5

Dickinson, J. L., Zuckerberg, B., \& Bonter, D. N. (2010). Citizen science as an ecological research tool: Challenges and benefits. Annual Review of Ecology, Evolution, and Systematics, 41(1), 149-172. https://doi.org/10.1146/annurev-ecolsys-102209144636

Fairweather, J. S. (2008). Linking Evidence and Promising Practices in Science, Technology, Engineering, and Mathematics ( STEM) Undergraduate Education A Status Report for The National Academies National Research Council Board of Science Education.

Freeman, S., Eddy, S. L., McDonough, M., Smith, M. K., Okoroafor, N., Jordt, H., \& Wenderoth, M. P. (2014). Active learning increases student performance in science, engineering, and mathematics. Proc Natl Acad Sci U S A, 111(23), 84108415. https://doi.org/10.1073/pnas.1319030111

Gonzalez, D., Hanke, G., Tweehuysen, G., Bellert, B., Holzhauer, M., Palatinus, A., . . Oosterbaan, L. (2016). Riverine Litter Monitoring - Options and Recommendations. MSFD GES TG Marine Litter Thematic Report. JRC Technical Report. EUR 28307. https://doi.org/10.2788/461233

Green, D. (2012). Using emerging technologies to facilitate science learning and civic engagement. Science Education and Civic Engagement, 4(2), 18-33.

Henderson, C., Beach, A., \& Finkelstein, N. (2011). Facilitating change in undergraduate STEM instructional practices:An analytic review of the literature. Journal of Research in Science Teaching 48(8), 952-984. https://doi.org/10.1002/tea.20439

Jang, H. (2016). Identifying 21st century STEM competencies using workplace data. Journal of Science Education and Technology, 25(2), 284-301. https://doi.org/10.1007/s10956-015-9593-1

Kiessling, T., Knickmeier, K., Kruse, K., Brennecke, D., Nauendorf, A., \& Theil, M. (2019). Plastic Pirates sample litter at rivers in Germany - Riverside litter and litter sources estimated by schoolchildren. Environmental Pollution, 245, 545-557. https://doi.org/10.1016/j.envpol.2018.11.025

Lasut, M. T., Weber, M., Pangalila, F., Rumampuk, N. D. C., Rimper, J. R. T. S. L., Warouw, V., . . Lott, C. (2018). From Coral Triangle to Trash Triangle-How the Hot spot of Global Marine Biodiversity Is Threatened by Plastic Waste, Cham.

Lebreton, L. C. M., van der Zwet, J., Damsteeg, J. W., Slat, B., Andrady, A., \& Reisser, J. (2017). River plastic emissions to the world's oceans. Nature Communications, 8, 15611. https://doi.org/10.1038/ncomms15611

lyer-Raniga, U., \& Andamon, M. (2016). Transformative learning: innovating sustainability education in built environment. International Journal of Sustainability in Higher Education, 17(1), 105-122. https://doi.org/10.1108/IJSHE-09-2014-0121

Montgomery, C., \& Fernandez-Cardenas, J. (2018). Teaching STEM education through dialogue and transformative learning: global significance and local interactions in Mexico and the UK. Journal of Education for Teaching, 44, 2-13. https://doi.org/10.1080/02607476.2018.1422606

Moore, S., Cover, M., \& A, S. (2007). A Rapid Trash Assessment Method Applied to Waters of the San Francisco Bay Region: Trash Measurement in Streams. https://www.waterboards.ca.gov/sanfranciscobay/docs/ swampthrashreport.pdf: Regional Water Quality Control Board, San Francisco Bay Region, Surface Water Ambient Monitoring Program.

National Academy of Sciences, E. a. M. (2017). Undergraduate Research experiences for STEM students: Successes, challenges, and opportunities. Washington, DC: The National Academies Press.

Rochman, C. M., Browne, M. A., Halpern, B. S., Hentschel, B. T., Hoh, E., Karapanagioti, H. K., . . Thompson, R. C. (2013). Classify plastic waste as hazardous. Nature, 494(7436), 169-171. https://doi.org/10.1038/494169a 
Russell, S., Hancock, M., \& McCullough, J. (2007). Benefits of undergraduate research experiences. Science, 316, 548549.

Shadle, S. E., Marker, A., \& Earl, B. (2017). Faculty drivers and barriers: Laying the groundwork for undergraduate STEM education reform in academic departments. International Journal of STEM Education, 4(1), 8. https://doi.org/10.1186/s40594-017-0062-7

Singleton, J. (2015). Head, heart and hands model for transformative learning: place as context for changing sustainability values. Journal of Sustainability Education, 9, $1-1$.

Stains, M., Harshman, J., Barker, M. K., Chasteen, S. V., Cole, R., DeChenne-Peters, S. E., ... Young, A. M. (2018). Anatomy of STEM teaching in North American universities. Science, 359(6383), 1468-1470. https://doi.org/10.1126/science.aap8892

Thiry, H., Laursen, S., \& Hunter, A.-B. (2011). What experiences help students become scientists?: a comparative study of research and other sources of personal and professional gains for STEM undergraduates. The Journal of Higher Education, 82(4), 357-388. https://doi.org/10.1080/00221546.2011.11777209

Wilson, Z. S., Iyengar, S. S., Pang, S.-S., Warner, I. M., \& Luces, C. A. (2012). Increasing access for economically disadvantaged students: The NSF/CSEM \& S-STEM programs at Louisiana State University. Journal of Science Education and Technology, 21(5), 581-587. https://doi.org/10.1007/s10956-011-9348-6

Zydney, A., Bennett, J., Abdus, S., \& Bauer, K. (2002). Faculty perspectives regarding the undergraduate research experience in science and engineering. Journal of Engineering Education, 91(3), 291-297. https://doi.org/10.1002/j.2168-9830.2002.tb00706.x 